\title{
STILE KEPENGARANGAN TENAS EFFENDY DALAM TUNJUK AJAR MELAYU
}

\author{
(Effendy Tennas Author Stile In A Tunjuk Ajar Melayu)
}

\author{
Oleh : Sri Rahayu* Alber** Viora*** \\ E-mail : srirahayu@edu.uir.ac.id \\ alber@edu.uir.ac.id
}

*) Program Studi Pendidikan Bahasa dan Sastra Indonesia FKIP UIR

\begin{abstract}
Literary works are classified as works of imagination in the form of fictional or imaginary experiences. The messages to be conveyed through literary works must be creative so that they appear attractive to read and listen to, so it is necessary to have a stile from the authorship itself to make his work beautiful and attractive. There are many ways to enjoy, understand and appreciate the work of the author Tenas Effendy, one of which is by studying the Stile of Tenas Effendy's authorship in Tunjuk Ajar Melayu. This study aims to analyze and interpret Tenas Effendy's stile authorship in Tunjuk Ajar Melayu. This needs to be examined because the existence of a literary work can be seen from how the author packs his work so that he can create his own stile from the author's side. The method used in this research is content analysis method. The source of data in this research is Tunjuk Ajar Melayu Karya Tenas Effendy in 2013 which has been recorded. The data collection technique is done by applying the hermeneutic technique. After the author of the analysis, Tunjuk Ajar Melayu by Tenas Effendy has a unique and distinctive authorship stile seen from the stylistic aspect, namely the stile as a pack of thoughts, the stile as a deviation from linguistic norms and the stile as a collection of personal characteristics.
\end{abstract}

Keyword: Stile, Author, Tunjuk Ajar Melayu

\section{PENDAHULUAN}

Stile kepengarangan sangat penting dimiliki seorang sastrawan agar dapat menghasilkan sebuah karya sastra yang berkualitas. Setiap pengarang memiliki stile yang berbeda-beda dalam menghasilkan sebuah karya sastra. Stile kepengarangan inilah yang mempengaruhi eksistensi seorang sastrawan karena stile tersebut akan menjadi ciri khas dari sastrawan tersebut. Tenas Effendy memiliki gaya atau stile kepengarangan yang unik dalam menghasilkan karya sastra yang berupa syair.

Stile yang akan dibahas dalam objek kajian ini menyangkut beberapa aspek di antaranya, stile sebagai bungkusan pikiran, stile sebagai penyimpangan dari norma kebahasaan, dan stile sebagai sekumpulan ciri pribadi. Tenas Effendy cukup bervariatif dan selektif dalam melakukan pemilihan kata, di mana kata tersebut yang berfungsi untuk membungkus pikiran dari seorang Tenas Effendy. Sebagai contoh stile kepengarangan dalam aspek stile sebagai bungkusan pikiran yang terdapat dalam Tunjuk Ajar Melayu Karya Tenas Effendy ini yaitu:

Apabila bekerja membanting tulang, Hidup ternama mati terbilang Apabila bekerja sepenuh hati 


\section{Kemana pergi orang hormati}

Dari contoh tersebut di atas pada baris pertama merupakan pola penggunaan dan pemilihan kata yang diterapkan oleh penulis yaitu dengan memilih kata membanting tulang dari pada menerapkan kata rajin sebagai sandingan kata bekerja. Pemilihan kata membanting tulang inilah yang berfungsi sebagai bungkusan pikiran pengarang.

\section{METODE PENELITIAN}

Penelitian ini menggunakan desain penelitian kualitatif deskriptif dengan instrumen penelitian berupa Buku Tunjuk Ajar Melayu karya Tenas Effendy terbitan Juni 2013 khususnya syair. Kegiatan penelitian ini dilakukan pada bulan Februari sampai bulan Juli 2020 dimulai dari kegiatan perencanaan penelitian dengan pengajuan proposal sampai pada tahap kegiatan pelaporan hasil penelitian.

Pengumpulan data dilakukan dengan metode deskriptif dan analisis isi yakni dengan cara mengumpulkan dan memilah-milah kutipan yang mengandung aspek stile kepengarangan Tenas Effendy dalam Tunjuk Ajar Melayu khususnya Syair. Kemudian kutipan yang mengandung aspek stile kepengarangan Tenas Effendy dalam Syair tersebutlah yang akan menjadi sampel penelitian. Setelah itu, barulah sampel yang didapatkan dianalisis dengan teori yang telah ditentukan.

\section{HASIL}

Berdasarkan pengumpulan data yang dilakukan oleh penelti tentang analisis stile kepengarangan dalam tunjuk ajar melayu karya Tenas Effendy khususnya syair dikaji dari aspek bungkusan pikiran, penyimpangan dari norma kebahasaan dan sekumpulan ciri pribadi sebagai berikut.

\section{Tabel 1. Bungkusan Pikiran Tunjuk Ajar Melayu dalam Syair Karya Tenas Effendy}

\begin{tabular}{|c|c|c|c|}
\hline \multirow{2}{*}{ NO } & \multirow{2}{*}{ Kutipan } & \multicolumn{2}{|c|}{$\begin{array}{c}\text { Bungkusan } \\
\text { Pikiran }\end{array}$} \\
\hline & & $\begin{array}{c}\text { Denot } \\
\text { asi }\end{array}$ & Konotasi \\
\hline 1 & $\begin{array}{c}\text { Wahai ananda permata ibu } \\
\text { Kepada Allah kita bertumpu } \\
\text { Semoga iman melekat dalam kalbu } \\
\text { Di jalan yang lurus kita menuju }\end{array}$ & & $\sqrt{ }$ \\
\hline 2 & $\begin{array}{l}\text { Wahai ananda cahaya mata } \\
\text { Peganglah pesan ibu dan bapa } \\
\text { Kepada Allah tempat meminta } \\
\text { Supaya hidupmu tidak bernista }\end{array}$ & & $\sqrt{ }$ \\
\hline 3 & $\begin{array}{l}\text { Wahai ananda buah hati ayah } \\
\text { Banyaklah sujud menyembah Allah } \\
\text { Mohon ampunan beserta hidayah } \\
\text { Hidup dan mati iman tak goyah }\end{array}$ & & $\sqrt{ }$ \\
\hline 4 & $\begin{array}{c}\text { Apabila imanmu sudah tercabut } \\
\text { Banyak perangai yang tidak patut } \\
\text { Tamak serakah bercampur kedekut } \\
\text { Di kaki setan ananda berlutut }\end{array}$ & & $\sqrt{ }$ \\
\hline 5 & $\begin{array}{l}\text { Apabila amanah sudah dipangku } \\
\text { Banyakkan sabar kendalikan nafsu } \\
\text { Hilangkan rasa bimbang dan ragu } \\
\text { Supaya tercapai hajat dituju }\end{array}$ & & $\sqrt{ }$ \\
\hline
\end{tabular}

\section{Tabel 2. Penyimpangan norma kebahasaan Tunjuk Ajar Melayu dalam Syair Karya Tenas Effendy}

\begin{tabular}{|c|c|c|}
\hline NO & Kutipan & $\begin{array}{c}\text { Penyimpangan norma } \\
\text { kebahasaan }\end{array}$ \\
\hline 1 & $\begin{array}{l}\text { Wahai ananda permata ibu } \\
\text { Kepada Allah kita bertumpu } \\
\text { Semoga iman melekat dalam kalbu } \\
\text { Di jalan yang lurus kita menuju }\end{array}$ & Wahai ananda permata ibu \\
\hline 2 & $\begin{array}{l}\text { Wahai ananda cahaya mata } \\
\text { Peganglah pesan ibu dan bapa } \\
\text { Kepada Allah tempat meminta } \\
\text { Supaya hidupmu tidak bernista }\end{array}$ & $\begin{array}{l}\text { Wahai ananda cahaya } \\
\text { mata }\end{array}$ \\
\hline 3 & $\begin{array}{l}\text { Wahai ananda buah hati ayah } \\
\text { Banyaklah sujud menyembah Allah } \\
\text { Mohon ampunan beserta hidayah } \\
\text { Hidup dan mati iman tak goyah }\end{array}$ & Wahai ananda buah hati \\
\hline 4 & $\begin{array}{l}\text { Apabila imanmu sudah tercabut } \\
\text { Banyak perangai yang tidak patut } \\
\text { Tamak serakah bercampur kedekut } \\
\text { Di kaki setan ananda berlutut }\end{array}$ & $\begin{array}{c}\text { Apabila iman sudah } \\
\text { tercabut }\end{array}$ \\
\hline 5 & $\begin{array}{l}\text { Apabila amanah sudah dipangku } \\
\text { Banyakkan sabar kendalikan nafsu } \\
\text { Hilangkan rasa bimbang dan ragu } \\
\text { Supaya tercapai hajat dituju }\end{array}$ & $\begin{array}{c}\text { Apabila amanah sudah } \\
\text { dipangku }\end{array}$ \\
\hline
\end{tabular}




\section{PEMBAHASAN}

\section{Bungkusan Pikiran Tunjuk Ajar Melayu dalam Syair Karya Tenas Effendy}

Data 1

Wahai ananda permata ibu

Kepada Allah kita bertumpu

Semoga iman melekat dalam kalbu

Di jalan yang lurus kita menuju

Kutipan data 1 larik 1 pada syair tersebut menunjukkan bahwa pengarang menggunakan kata permata untuk mengungkapkan betapa berharganya seorang anak bagi orangtua atau ibu. Pengarang sangat tepat sekali dalam menggunakan kata permata untuk membungkus sebutan seorang anak yang sangat disayangi dan sangat berharga oleh ibunya. Stile sebagai bungkusan pikiran merupakan stile atau gaya yang digunakan oleh pengarang untuk mengemas atau membungkus sebuah kata sehingga kata tersebut memiliki nilai estetika yang tinggi. Sebagai pengarang memang sangat perlu untuk bisa memilih dan menetapkan sebuah kata dalam karyanya. Semakin tepat pengarang membungkus kata dalam karyanya maka semakin baik juga nilai kualitas karya sastra tersebut.

\section{Penyimpangan Norma Kebahasaan Tunjuk Ajar Melayu dalam Syair Karya Tenas Effendy}

\section{Data 2}

Wahai ananda cahaya mata Peganglah pesan ibu dan bapa Kepada Allah tempat meminta Supaya hidupmu tidak bernista

Penyimpangan norma kebahasaan terdapat pada Kutipan syair data 2 larik 1 wahai ananda cahaya mata. Kata cahaya mata yang digunakan oleh pengarang untuk menyebutkan panggilan kepada sang anak. Penyimpangan norma kebahasaan terletak pada kata cahaya mata yang dipakai oleh pengarang. Anak merupakan keturunan bagi setiap orang tua namun pengarang melakukan penyimpangan norma dalam penulisan hasil pikirannya dengan menyebutkan bahwa anak sebagai cahaya mata bagi orang tua. Larik 2 juga terdapat penyimpangan norma kebahasaan yang ditulis oleh pengarang yaitu peganglah pesan ibu dan bapak. Seharusnya pesan kedua orang tua harusnya senantiasa diingat dan diterapkan dalam hidup tapi dalam hal ini pengarang mengganti kata diingat dengan kata pegang.

Data 10

Apabila amanah sudah dipikul Asahlah otak supaya tak tumpul Laksanakan dengan baik dan betul Supaya namamu tidak tercabul

Kutipan syair pada data 10 larik 1 dan 2 terdapat penyimpangan norma kebahasaan yaitu apabila amanah sudah dipikul, asahlah otak supaya tak tumpul. Penyimpangan norma kebahasaan ada pada kata amanah yang membungkus kata kepercayaan, dipikul untuk membungkus kata beban yang dibawa di atas bahu seseorang. Selain itu penyimpangan juga terdapat pada kata asah dan tumpul. Kata asah digunakan pengarang untuk membungkus kata gosok berulang-ulang, kata tumpul untuk membungkus kata tidak tajam. Penyimpangan norma kebahasaan yang dilakukan pengarang bertujuan untuk membuat penulisan kosa kata yang ada dalam syair menjadi lebih baik dan berkualitas. Kutipan apabila amanah sudah dipikul, asahlah otak supaya tak tumpul memiliki maksud yang ingin disampaikan pengarang bahwa jika seseorang telah diberikan beban kepercayaan maka rajinlah belajar atau menggunakan otak untuk berfikir kritis agar tidak menjadi orang yang bodoh atau tidak berilmu. 
Gambar 1. Sekumpulan Ciri Pribadi Tunjuk Ajar Melayu dalam Syair Karya Tenas Effendy

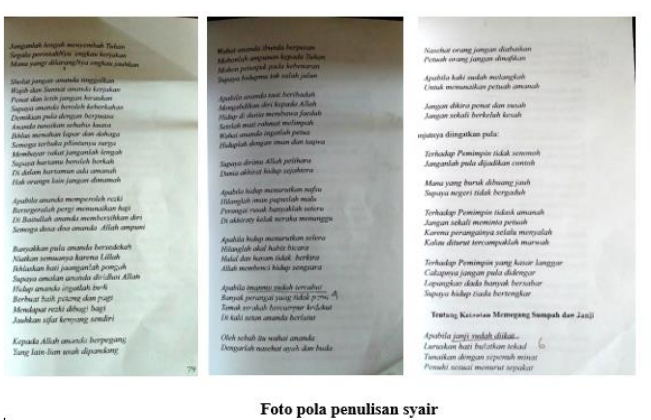

Sekumpulan ciri pribadi merupakan gaya kepengarangan seorang pengarang dalam menciptakan sebuah karya sastra. Setiap pengarang memiliki ciri tersendiri dalam menghasilkan sebuah karya sastra. Sebuah karya sastra akan memiliki kualitas yang berbeda antara setiap pengarang, semakin banyak dan baik kualitas perbendaharaan kata yang dimiliki oleh seorang pengarang akan memengaruhi kualitas hasil karya yang dihasilkannya. Tidak jarang kualitas tersebut akan menjadi ciri khas seseorang dalam setiap karya yang diciptakannya. Penulisan syair yang dituliskan oleh Tenas Effendy sudah mengikuti pola penulisan syair yang benar di antaranya pola penulisan rima yaitu a-aa-a, bahasa yang digunakan merupakan makna kiasan, namun hanya saja pembentukkan tipografi yang tidak konsisten telah digunakan oleh pengarang, setiap bait syair pola penulisan baris atau lariknya berjumlah berbeda- beda dan tidak konsisten penggunaan pola 4 baris, ada yang 2 larik bahkan ada yang berjumlah 8 larik dalam setiap bait syair. Hal inilah yang menjadi ciri khas pengarang dalam menciptakan sebuah karya sastra khususnya syair. Pola baris dalam bait inilah yang merupakan ciri pribadi seorang Tenas Effendy dalam menciptakan syair yang berkualitas di mata penikmat sastra.

\section{IMPLIKASI}

Berdasarkan hasil pembahasan dan analisis stile kepengarangan Tunjuk Ajar
Melayu dalam Syair dari aspek bungkusan pikiran, penyimpangan norma kebahasaan dan ciri pribadi pengarang dapat disimpulkan bahwa pengarang telah mampu membungkus pikirannya dengan kualitas pilihan kata yang tepat. Setiap kata dibungkus oleh pengarang dengan katakata yang memiliki makna kiasan yang tepat dan memiliki kualitas estetika yang tepat. Penyimpangan norma kebahasaan yang terdapat dalam penulisan syair memang dilakukan dan diterapkan pengarang disetiap bait syair hal ini dilakukan pengarang agar syair tesebut memiliki kadar kualitas yang baik di mata penikmatnya. Aspek ciri pribadi memang terdapat dalam penulisan syair tersebut diantaranya dari pola penulisan jumlah baris atau larik dalam setiap bait syair yang dihasilkan. Setiap bait syair terdiri dari berbagai larik atau baris ada yang berjumlah 2 larik, 4 larik bahkan ada yang berjumlah 8 larik sehingga peneliti dapat menyimpulkan bahwa dalam penulisan pola bait syair pengarang tidak konsisten menerapkan pola baris ini, namun untuk ciri yang lain pengarang sudah mengikuti pola pembuatan syair yang sesuai dengan teori syair. Hal inilah yang menjadi ciri khas seorang Tenas Effendy dalam menciptakan sebuah karya sastra khususnya syair

\section{REFERENSI}

Abidin, Zainal. 2010. „Analisis

Stilistika Pantun Manjopuik

Limau Desa Benai Kabupaten

Kuantan Sengingi”. Skripsi.

Pekanbaru: FKIP Universitas

Islam Riau.

Arpen, Hidayat. 2016. "Analisis

Gaya Bahasa dan Makna Pantun

Adat Perkawinan Desa Tanjung

Kecamatan Koto Kampar Hulu

Kabupaten Kampareee. Skrips.

Pekanbaru: FKIP Universitas

Islam Riau Pekanbaru.

Endraraswara, Suwanda, 2011.

Metodologi Penelitian Sastra 
(Epistemologi, Model, Teori, dan Aplikasi). Yogyakarta: CAPS.

Ernawati, Waridah, 2013. Ejaan yang Disempurnakan dan Seputar Kebahasaan Indonesia. Bandung: Ruang Kata.

Fatimah, Rezki Puteri Syahrani Nurul. 2015. "Tunjuk Ajar Melayu dalam Pantun Adat Perkawinan Melayu Kelurahan Daik Kabupaten Lingga Kepulauan Riau ${ }^{\text {eeee }}$. Jurnal Bahas Volume 10 Nomor 2 Oktober. (http://www.google.co.id, diakses 25 Juli 201709:25.

Hamidy, UU. 2005. Pembahasan Karya Fiksi dan Puisi. Pekanbaru: Unri Press. . 2009. Jagad Melayu dalam

Lintasan Budaya. Pekabaru: Bilik Kreatif Pres.

Keraf, Gorys. 2010. Diksi dan Gaya bahasa. Jakarta: Gramedia Pustaka Utama.

Kridalaksana, H.2008. Kamus linguistik. Jakarta: PT. Gramedia Pustaka Utama.

Krippendorff, Kalus. 1991. Analisis Isi: Pengantar Teori dan Metodologi. Jakarta: Rajawali Pers.

Mahsun. 2007. Metode Penelitian Bahasa. Jakarta: PT Raja Grafindo Persada

Nurgiyantoro, Burhan. 2014. Stilistika. Yogyakarta: Gadjah Mada University Press.

Pusat Pembinaan dan Pengembangan Bahasa. 2008. Kamus Besar Bahasa Indonesia: Edisi ke-4. Jakarta: Gramedia Pustaka Utama

Ratna, Nyoman Kutha. 2009. Stilistika: Kajian Puitika Bahasa Sastra dan Budaya. Yogyakarta: Pustaka Pelajar.

Rokhmansyah. 2014. Studi dan Pengkajian Sastra: Perkenalan
Awal Terhadap Ilmu Sastra.

Yogyakarta: Graha Ilmu.

Sikana, Mana. 1990. Pendekatan Kesusastraan Modern. Bani Selangor: Penerbit Karyawan.

Sudjiman, Panuti. 1993. Bunga Rampai Stilistika. Jakarta: Grafiti.

Sugiyono. 2014. Memahami Penelitian Kulitatif. Bandung:Alfabeta. 